\title{
Thrombogenic changes in young and old mice upon subchronic exposure to air pollution in an urban roadside tunnel
}

\author{
Jan Emmerechts'; Vanessa De Vooght'; Steven Haenen²; Serena Loyen'; Soetkin Van kerckhoven'; Bianca Hemmeryckx'; \\ Jeroen A. J. Vanoirbeek ${ }^{2}$; Peter H. Hoet ${ }^{2}$; Ben Nemery ${ }^{2}$; Marc F. Hoylaerts ${ }^{1}$ \\ ${ }^{1}$ Center for Molecular and Vascular Biology, University of Leuven, Belgium; ${ }^{2}$ Occupational \& Environmental Medicine, Unit of lung toxicology, University of Leuven, Belgium
}

\begin{abstract}
Summary
Epidemiological studies indicate that elderly persons are particularly susceptible to the cardiovascular health complications of air pollution, but pathophysiological mechanisms behind the increased susceptibility remain unclear. Therefore, we investigated how continuous traffic-related air pollution exposure affects haemostasis parameters in young and old mice. Young ( 10 weeks) and old ( 20 months) mice were placed in an urban roadside tunnel or in a clean environment for 25 or 26 days and markers of inflammation and endothelial cells or blood platelet activation were measured, respectively. Plasma microvesicles and pro/ anticoagulant factors were analysed, and thrombin generation analysis was performed. Despite elevated macrophage carbon load, tunnel mice showed no overt pulmonary or systemic inflammation, yet manifested reduced pulmonary thrombomudulin expression and elevated endothelial von Willebrand factor (VWF) expression in lung capillaries. In young mice, soluble P-selectin (sP-sel) increased with exposure and cor-
\end{abstract}

\section{Correspondence to:}

Marc Hoylaerts

Center for Molecular and Vascular Biology

Herestraat 49, B-3000 Leuven, Belgium

Tel.: +3216 346145, Fax: +3216345990

E-mail: marc.hoylaerts@med.kuleuven.be related with soluble E-selectin and VWF. Baseline plasma factor VIII (FVIII), sP-sel and VWF were higher in old mice, but did not pronouncedly increase further with exposure. Traffic-related air pollution markedly raised red blood cell and blood platelet numbers in young and old mice and procoagulant blood platelet-derived microvesicle numbers in old animals. Changes in coagulation factors and thrombin generation were mild or absent. Hence, continuous traffic-related air pollution did not trigger overt lung inflammation, yet modified pulmonary endothelial cell function and enhanced platelet activity. In old mice, subchronic exposure to polluted air raised platelet numbers, VWF, sPsel and microvesicles to the highest values presently recorded, collectively substantiating a further elevation of thrombogenicity, already high at old age.

\section{Keywords}

Air pollution, haemostasis, microvesicles, endothelium, blood platelets

Received: March 12, 2012

Accepted after major revision: July 31, 2012

Prepublished online: August 7, 2012

doi:10.1160/TH12-03-0161

Thromb Haemost 2012; 108: 756-768

\section{Introduction}

Over the last two decades, a large body of epidemiological research has consistently demonstrated an association between exposure to air pollution and cardiovascular disease and mortality (1-7). Both gaseous (carbon monoxide, nitrogen oxides, sulfur dioxide, ozone) and particulate components (particulate matter, PM) are implicated in air pollution (8), but the larger body of evidence points towards the deleterious effects of the particulates, as recently concluded (9). Both acute and chronic cardiovascular health effects are described. Thus, exposure to PM for as little as 2 hours (h) suffices to trigger myocardial infarction (10), findings confirmed via diesel exhaust inhalation studies, accompanied by increased thrombogenicity (11) and inhibition of the endogenous fibrinolytic capacity (12). More chronic exposure, such as living near a major road, has been associated with increased coronary artery calcification, a measure for atherosclerosis (13), and with an enhanced risk for venous thrombosis (14). In view of its omnipresent exposure in modern society, traffic-related air pollution is believed to represent a major public health burden (9).

Because of a gradual physiological decline and higher prevalence of pre-existing cardiovascular and respiratory risk factors, elderly persons ( $>65$ years of age) are believed to be more susceptible to deleterious cardiovascular effects triggered by air pollution than younger people (15). PM exposure-related relative risk estimates appear to be higher in elderly, both for mortality $(4,7,16)$ and hospitalisation for cardiovascular disease $(17,18)$. Similarly, the relative risk for cardiovascular disease associated with gaseous pollutants is increased in the very elderly ( $\geq 75$ years of age) (19). Even though an association between age and increased relative risk for air pollution-related cardiovascular disease was not found in all studies, the attributable risk, an estimate depending both on the strength of the association between risk factor and disease and its prevalence, was highest among the elderly, due to their higher baseline risk (19). Indeed, the elderly not only have a higher baseline risk for developing myocardial infarction (20), but they also show 
a strongly upregulated tendency for venous thrombogenicity, linked to elevation of several coagulation factors $(21,22)$. Yet, despite growing epidemiological evidence of raised cardiovascular risk associations with air pollution exposure in the elderly, it is not known whether and how air pollution affects haemostasis and blood parameters at advanced age.

In the current study, therefore, we investigated the consequences of traffic-related air pollution on haemostasis in young vs. old mice. In mice, short-term experimental exposure via intratracheal instillation of PM was inadequate to induce changes in secondary haemostasis parameters (23). Therefore, we placed young and old mice in an urban roadside tunnel and analysed blood parameters and haemostasis, after 25 or 26 days of exposure to polluted air, in comparison to partial and non-exposed groups. In addition to a detailed analysis of parameters of haemostasis in the lung and plasma, plasma was analysed for microvesicles (also called microparticles, a term we prefer to avoid in the context of pollution by particles), since negatively charged phospholipids and tissue factor (TF) on their membranes manifest procoagulant properties, via binding of coagulation factors (24). An association between PM exposure and the number of circulating microvesicles was recently demonstrated in diabetic persons (25).

\section{Materials and methods}

\section{Mice}

This study was approved by the Institutional Review Board of the University of Leuven, and experiments were performed in accordance with protocols approved by the Institutional Animal Care and Research Advisory Committee. Male C57Bl6/j mice aged 10 weeks ('young') or 20 months ('old') were purchased from Janvier (Le Genest St Isle, France).

\section{Experimental design}

Mice were randomly allocated to one of three groups: a first group ('clean') remained in the animal facility of the University of Leuven during the whole period of the experiment. They were kept in micro-isolation cages covered by a conventional filter top (Tecniplast, Buggiate, Italy) in a light-controlled (14/10-h day/night cycle) room with continuous air filtration. The second ('tunnel-filtered') and third ('tunnel-exposed') groups were stationed in an urban roadside tunnel (Craeybeckx tunnel, Antwerp, Belgium) at $57 \mathrm{~km}$ from the University of Leuven. This tunnel is a major motorway of car and truck traffic entering Antwerp. It is 1,600 m long and consists of separate pipes for each direction, each comprising four lanes. Mice were placed in an alcove inside the tunnel, close to the end of one of the pipes and at $4 \mathrm{~m}$ distance of the bypassing traffic. Preliminary measurements demonstrated that PM concentrations were highest at this location of the tunnel (data not shown). Mean daily counts for vehicle traffic in 2010 for this pipe were 49,780 non-trucks and 6,545 trucks (source: Department Mobility and Public Works - Division Traffic Centre of the Flemish government, unpublished data). Mice allocated to the 'tunnel-filtered' group were placed in micro-isolation cages covered with two layers of highly efficient flexible filter material (Pads F7, Camfil Farr, Zaventem, Belgium, minimum life efficiency on $0.4 \mu \mathrm{m}$ : $\geq 35 \%$ ), separated by about $5 \mathrm{~cm}$ of air. Mice allocated to the 'tunnel-exposed' group were placed in the same location in micro-isolation cages without filter tops, placed adjacent to each other. For all three groups, mice had access to food and water ad libitum and cages were cleaned once a week ( $n=7-8$ per group). The total study period was 25-26 days.

\section{Exposure measurements}

PM measurements were performed every 30 minutes ( $\mathrm{min}$ ) during the entire exposure period, using a portable laser-operated aerosol mass analyzer (Aerocet 531, Met One Instruments Inc, Grant Pass, OR, USA) inside empty cages, placed among the mouse-containing cages, in the tunnel and control sites. PM concentrations were also assessed on a single occasion by sampling PM on a glass microfibre filter (Whatman, Kent, UK) by using a sampling pump (SP350, TSI, Shoreview, USA) at $21 /$ min over $10 \mathrm{~h}$. Data on the tunnel traffic during the study period were collected through courtesy of the Department Mobility and Public Works - Division Traffic Centre of the Flemish government in Belgium. No gas collection was done in this study.

\section{Blood collection}

At the end of the exposure period (25-26 days), mice were anesthetised (sodium pentobarbital, $60 \mathrm{mg} / \mathrm{kg}$, i.p.) and blood was collected from the retroorbital sinus on citrate $0.38 \%$ or on EDTA. Blood cell counts and differentials were performed on a Cell-Dyn 3500R counter (Abbott, Diegem, Belgium). Citrated samples were centrifuged twice (1,500 g x $15 \mathrm{~min}$ ), and plasma was snap frozen in liquid nitrogen and stored at $-80^{\circ} \mathrm{C}$ for subsequent coagulation and microvesicle assays. EDTA-anticoagulated blood was centrifuged once $(15,000 \mathrm{~g} \mathrm{x} 10 \mathrm{~min})$ and plasma stored at $-20^{\circ} \mathrm{C}$ for antigen determinations.

\section{Bronchoalveolar lavage and lung tissue collection}

Following blood sampling, the mouse abdomen and thorax were opened. The left bronchus was ligated and the trachea exposed and cannulated with a 20 Gauge cannula to lavage the right lung three times with $0.4 \mathrm{ml}$ (total volume of $1.2 \mathrm{ml}$ ) of sterile $\mathrm{NaCl} 0.9 \%$. The recovered bronchoalveolar lavage fluid (BALF) aliquots were 
pooled and placed on ice. No difference in the volume of collected fluid was observed between groups. Cells in fresh BALF were stained with Trypan Blue and counted in a Bürker hemocytometer. Cell differentials were determined by light microscopy on cytocentrifuge preparations fixed in methanol and stained with Diff Quick (Siemens, Brussels, Belgium). The remaining BALF was then centrifuged (1,000 g x $10 \mathrm{~min}$.) and the supernatant stored at $-20^{\circ} \mathrm{C}$ for cytokine analysis. Upon bronchoalveolar lavage, the left lung was filled with $0.4 \mathrm{ml}$ parafomaldehyde $4 \%$ (PFA), isolated and immersed in PFA 4\% for fixation.

\section{Carbon load}

Airway macrophages were visualised by light microscopy (AxioPlan 2 Imaging, Zeiss, Zaventem, Belgium) and pictures were taken with Axiovision Rel. 4.6. (Zeiss, Jena, Germany). ImageJ software (version 1.440, National Institutes of Health, Bethesda, MD, USA) was used to calculate the carbon load of airway macrophages via surface analysis, as described previously $(26,27)$. First, the nucleus was removed from the image of each macrophage. Then, carbon load was defined as the median area $\left(\mu \mathrm{m}^{2}\right)$ occupied by carbon, in at least 20 randomly selected macrophages per mouse.

\section{Histology, immunohistochemistry}

Lung tissues of three randomly chosen mice per group were embedded in paraffin, and $8 \mu \mathrm{m}$ cross-sections were stained with hematoxylin and eosin (H\&E) or von Willebrand factor (VWF) using rabbit anti-human VWF antibody (cross-reactive with murine VWF, dilution 1/50) and a biotinylated secondary goat anti-rabbit antibody (both Dako, Heverlee, Belgium). All slides were stained at the same time and for an identical reaction time. Stainings were analysed with a Zeiss AxioPlan 2 Imaging microscope (Zeiss) and pictures were taken with Axiovision Rel. 4.6. (Zeiss). Per mouse, the intensity of the endothelial VWF staining was manually scored by three independent and blinded observers, excluding intravascular, i.e. platelet-associated VWF, via a simple graded score of 1,2 or 3 , corresponding to light, moderate or intense staining, respectively, for each section. Pulmonary thrombomodulin was stained with a goat anti-mouse $409 \mathrm{TM}$ antibody $(0.2 \mu \mathrm{g} / \mathrm{ml})$, as recently reported (28). The specificity of thrombomodulin staining was confirmed by prior incubation of the $409 \mathrm{TM}$ antibody with an excess of recombinant mouse thrombomodulin (R\&D Systems, Minneapolis, MN, USA), which step eliminated subsequent antibody binding to lung sections completely. Staining of lung thrombospondin-1 (TSP-1) was done with home-made rabbit antiTSP-1 antibodies, adsorbed for cross-reactivity with TSP-2, as previously described (29).

\section{ELISA and Western blot of pulmonary proteins}

Isolated lungs were snap frozen at $-80^{\circ} \mathrm{C}$, and proteins were extracted by adding $4 \mu \mathrm{l}$ of protein extraction buffer $\left(\mathrm{Na}_{2} \mathrm{HPO}_{4} 10\right.$ $\mathrm{nM}, \mathrm{NaCl} 150 \mathrm{mM}$, Triton X-100 1\%, SDS 0.1\%, $\mathrm{C}_{24} \mathrm{H}_{39} \mathrm{NaO}_{4}$ $0.5 \%, \mathrm{NaN}_{3} 0.2 \%$ ) per mg of frozen tissue, followed by homogenisation with a Ribolyzer Fast Prep 24 system (MP Biomedicals, Brussels, Belgium). The protein concentration in these extracts was determined via the Bradford Protein Assay (Bio-Rad, München, Germany).

Thrombomodulin expression in total lung extracts was investigated via Western blotting, upon SDS-PAGE of total lung extracts on $7 \%$ gels and transfer to nitrocellulose. Western blot detection of intact thrombomodulin was by the same antibody, used for immunohistochemical staining. Quantification was performed through ImageJ software (version 1.440, NIH). Each value was first normalised to the value of a control sample, run on each gel, followed by a second normalisation over the value of the house-keeping protein $\beta$-actin, measured via the rabbit anti- $\beta$-actin monoclonal antibody 4970 (Cell Signaling, Bioké, Leiden, The Netherlands).

VWF expression in total lung extracts was investigated via ELISA, using rabbit anti-human VWF antibody and biotinylated anti-human VWF antibody (Dako, Heverlee, Belgium), as recently described (30). VWF concentrations $(\mu \mathrm{g} / \mathrm{ml})$ were normalised to the total protein concentration and expressed in $\mu \mathrm{g} / \mathrm{mg}$ protein.

\section{Coagulation assays}

All coagulation assays were performed on the BCS-XP coagulation analyzer (Siemens, Hamburg, Germany) using the manufacturer's reagents and adapted procedures for murine coagulation testing (31). Coagulation factor (F) VII and FVIII activity were determined by one-stage coagulation assays, calibrated with pooled murine plasma. Fibrinogen concentrations were determined by the functional Clauss method, calibrated with Standard Human Plasma (Siemens, Hamburg, Germany).

\section{Thrombin generation assays (TGA)}

Thrombin generation was measured in diluted plasma (1/4) by means of the Calibrated Automated Thrombography (CAT) method using a Fluoroskan Ascent reader (Thermo Labsystems OY, Helsinki, Finland). Thrombinoscope software (Thrombinoscope BV, Maastricht, The Netherlands) was used to calculate thrombin generation curves, from which the lag times, endogenous thrombin potential (ETP) and peak height were derived. TGA were performed in two ways: first, in the presence of $10 \mu \mathrm{M}$ phospholipids and in the absence of exogenously added tissue factor (TF) (condition called '+PL-TF'), and second, in the presence of both $10 \mu \mathrm{M}$ phospholipids and $0.3 \mathrm{pM}$ exogenously added TF (Innovin, Siemens, Marburg, Germany) (condition called '+PL+TF'). 


\section{Flow cytometric microvesicle analysis}

Flow cytometric analysis of microvesicles was performed as recently described (25). In brief, plasma was thawed at $37^{\circ} \mathrm{C}$, labelled with fluorescein isothiocyanate-labelled anti-CD41/61 (Emfret, Eibelstadt, Germany), phycoerythrin-labelled anti-Ter119 (BD Biosciences, Erembodegem, Belgium) and allophycocyanin-labelled annexin V (AV, Immunotools, Friesoythe, Germany) and analysed on a FACSCantoII flow cytometer (BD Biosciences) to define blood platelet-derived microvesicles ('BP- $\left.\mu \mathrm{V}^{\prime}\right)$ and red blood cell-derived microvesicles ('RBC- $\mu V^{\prime}$ ). Surface expression of negatively charged phospholipids was assessed by measuring annexin $\mathrm{V}$ binding ('AV').

\section{Antigen measurements in blood}

VWF mouse plasma levels were determined via ELISA, using the same methodology as described above. Commercial ELISA's were used to determine the concentrations of soluble P-selectin (sP-sel), soluble E-selectin (sE-sel), platelet factor 4 (PF4) (all R\&D Systems, Abingdon, UK) and interleukin-6 (IL-6, eBioscience, Vienna, Austria) in EDTA plasma.

\section{Statistical analysis}

We used non-parametrical Kruskal-Wallis tests with Dunn's multiple comparison post-tests to analyse significance between the different exposure groups within each age class, and Mann-Whitney tests to analyze significance between both age classes for mice placed in the 'clean' environment. All statistical analyses were performed using GraphPad Prism version 4.0b (GraphPad Software, San Diego, CA, USA).
Figure 1: Exposure characteristics. Levels of $\mathrm{PM}_{10}$ (upper graph, left $Y$-axis) and $\mathrm{PM}_{2.5}$ (lower graph, left Y-axis) were measured inside cages placed in both locations (as indicated), during the entire study period (days in X-axis). Dotted line represents total vehicle traffic transit through the roadside tunnel, calculated per hour (right Y-axis). The bottom panel shows glass microfibre filters on which PM was sampled in (from left to right) a cage in the clean environment, a filtered cage inside the roadside tunnel and an unfiltered cage inside the tunnel.

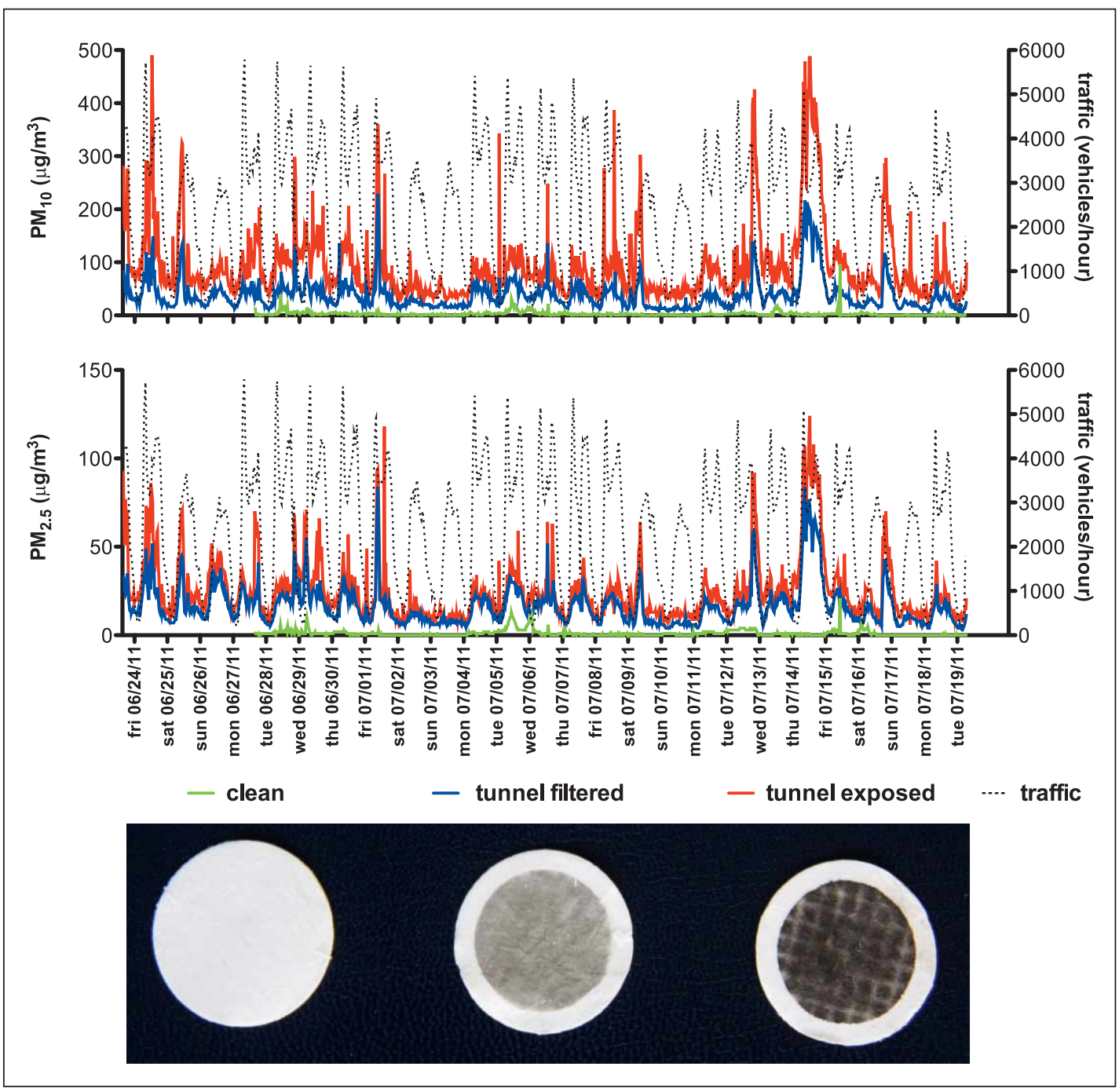




\section{Results}

\section{Exposure characteristics}

Figure 1 shows the measurements for $\mathrm{PM}_{10}(\mathrm{PM}$ with a mean diameter smaller than $10 \mu \mathrm{m})$ and for $\mathrm{PM}_{2.5}(\mathrm{PM}$ with a mean diameter smaller than $2.5 \mu \mathrm{m}$ ) at both locations, together with the hourly vehicle transit through the tunnel. In general, PM measurements paralleled vehicle transit data, with higher values on working days than on weekend days, and higher values during the morning rush hours. Mean levels of $\mathrm{PM}_{10}$, averaged over the entire study period, were $59 \%$ lower inside the filtered cages in the tunnel ('tunnel-filtered', 38.6 $\mu \mathrm{g} / \mathrm{m}^{3}$ ) and $97 \%$ lower inside the cages in the clean environment ('clean', $2.9 \mu \mathrm{g} / \mathrm{m}^{3}$ ), compared to the unfiltered cages in the tunnel ('tunnel-exposed', $93.8 \mu \mathrm{g} / \mathrm{m}^{3}$ ). For $\mathrm{PM}_{2.5}$, values were $32.3 \%$ lower for the 'tunnel-filtered' group $\left(16.8 \mu \mathrm{g} / \mathrm{m}^{3}\right)$ and $95.5 \%$ lower for the 'clean' group $\left(1.1 \mu \mathrm{g} / \mathrm{m}^{3}\right)$, compared to the 'tunnel-exposed' group $\left(24.9 \mu \mathrm{g} / \mathrm{m}^{3}\right)$. Correspondingly, the collection filter was considerably blacker upon sampling of unfiltered tunnel air than upon sampling of filtered tunnel air, while hardly any particulate material was sampled on the filter in the clean environment ( Fig. 1).

\section{Bronchoalveolar lavage cells and IL-6}

Baseline values (defined as the value for the 'clean group') of BALF WBC concentrations were higher in old mice than in young mice ( Table 1). Almost all BALF cells were monocytes/macrophages. Exposure to traffic-related air pollution did not influence WBC counts or differentiation in either age category (Table 1 and Fig. 2), despite the high carbon load in alveolar macrophages of the tunnel mice, which tended to be higher for the 'tunnel-exposed' than for the 'tunnel-filtered' group ( Fig. 2D). Concentrations of IL-6 in BALF were below the detection limit for all but two mice (in different groups).

\section{Haematological parameters and IL-6}

Results for blood cell counts are shown in Figure 3. Higher baseline values in old vs. young mice were observed for WBC, RBC, haemoglobin and blood platelet levels. Group-wise, WBC numbers were not affected by exposure to traffic-related air pollution, but a few individual animals showed a drop in WBC numbers. In contrast, values for RBC and haemoglobin increased significantly for the 'tunnel-filtered' and 'tunnel-exposed group' as compared to the 'clean' group, both in young and old mice. BP numbers also increased in all 'tunnel' groups, with the highest values found for some 'tunnel-exposed' old mice. Concentrations of IL-6 in plasma were below the detection limit for all but three mice (in different groups, not shown).

\section{Haemostasis parameters in the lung}

VWF was present in lung extracts (at constant extract volume per mg tissue) of old mice, in slightly higher concentrations. Yet, no strict

Table 1: Body weight, BALF cell counts and coagulation parameters in young and old mice.

\begin{tabular}{|c|c|c|c|c|c|c|}
\hline & \multicolumn{3}{|l|}{ Young } & \multicolumn{3}{|l|}{ Old } \\
\hline & clean & tunnel filtered & tunnel exposed & clean & tunnel filtered & tunnel exposed \\
\hline Final body weight (g) & $27.8(26.9-28.0)$ & $28.7(27.8-29.8)$ & $29.0(28.2-29.5)$ & $30.3(29.7-33.8)^{\pi}$ & $33.4(32.2-34.1)$ & $31.1(29.5-32.6)$ \\
\hline \multicolumn{7}{|l|}{ BALF cell count } \\
\hline 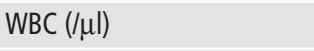 & $45.0(25.0-50.0)$ & $50.0(42.5-57.5)$ & $50.0(32.5-60.0)$ & $77.5(70.0-90.0)^{111}$ & $80.0(40.0-80.0)$ & $60.0(42.5-85.0)$ \\
\hline Neutrophils (\%) & $0.0(0.0-0.0)$ & $0.0(0.0-0.0)$ & $0.0(0.0-0.8)$ & $0.0(0.0-0.0)$ & $0.0(0.0-0.0)$ & $0.0(0.0-0.0)$ \\
\hline Monocytes (\%) & $100(99.3-100.0)$ & $99.5(97.5-100.0)$ & $100.0(99.0-100.0)$ & $99.5(97.5-100.0)$ & $99.0(96.0-100.0)$ & $98.5(98.0-100.0)$ \\
\hline \multicolumn{7}{|l|}{ Coagulation } \\
\hline Fibrinogen (mg/dl) & $199(172-221)$ & $188(181-207)$ & $196(173-226)$ & 191 (178-207) & 181 (171-201) & $192(182-201)$ \\
\hline FVII (\%) & $115(107-125)$ & $116(112-137)$ & $122(114-127)$ & $117(108-127)$ & $120(114-140)$ & $115(107-129)$ \\
\hline FVIII (\%) & $95(93-112)$ & $106(86-119)$ & $107(103-125)$ & $134(112-144)^{\text {กก }}$ & $111(103-128)$ & $120(111-129)$ \\
\hline TG (+PL-TF) lagtime (min.) & $9.0(5.8-14.7)$ & $10.7(10.0-13.3)$ & $14.7(7.1-14.8)$ & $17.3(10.3-60.0)$ & $13.5(7.7-17.8)$ & $14.3(11.7-60.0)$ \\
\hline TG (+PL-TF) ETP (nM.min) & $102(76-139)$ & $123(108-208)$ & $105(70-161)$ & $67(0-162)$ & $61(39-89)$ & $143(0-193)$ \\
\hline TG (+PL-TF) peak (nM) & $9.6(7.0-10.5)$ & $9.6(7.4-18.7)$ & $8.3(5.0-11.5)$ & $4.9(0.0-11.5)$ & $5.7(2.9-7.9)$ & $9.5(0.0-20.8)$ \\
\hline TG (+PL+TF) lagtime (min.) & $2.8(2.4-3.2)$ & $2.9(2.4-3.1)$ & $3.0(2.3-3.1)$ & $3.5(2.8-3.7)$ & $3.0(2.7-3.3)$ & $3.5(2.7-3.8)$ \\
\hline TG (+PL+TF) ETP (nM.min) & $296(279-320)$ & $375(350-422)^{* *}$ & $317(301-353)$ & $330(255-412)$ & $365(274-442)$ & $312(282-365)$ \\
\hline TG (+PL+TF) peak (nM) & $42.1(37.7-48.8)$ & $39.3(38.1-42.1)$ & $37.5(35.8-40.2)$ & $44.4(40.1-52.9)$ & $45.4(35.7-48.6)$ & $38.0(34.7-45.6)$ \\
\hline
\end{tabular}


VWF-induction was observed in 'tunnel-exposed' or 'tunnel-filtered' animals ( Fig. 4A). Normalising VWF-expression per total protein in the extract affected the results for young and old mice differently, but a higher normalised VWF-expression was maintained for the old 'tunnel-exposed' and 'tunnel-filtered' animals than for the young mice ( Fig. 4B). Therefore, lung sections were stained for VWF. Making abstraction of luminal platelet VWF, endothelial VWF-positivity was suggestive of higher expression, especially in the smaller pulmonary blood vessels for the 'tunnel-exposed' [mean (SD) score for young mice: 2.2 (0.8), old mice: $1.8(0.2)$ ] and the 'tunnel-filtered' groups [mean (SD) score for young mice: 2.7 (0.3), old mice: $2.4(0.4)$ ], as compared to the 'clean' group [mean (SD) score for young mice: 1.6 (0.7), old mice: 1.4 (0.2)] ( Fig. 4C). Additional immunohistochemical staining for thrombospondin-1 confirmed that in all cases, thrombospondin-1 was exclusively present in the vessel lumen, i.e. present in platelets, and was absent on the vessel wall (not shown). Thus, the elevated VWF-staining in the endothelium was not the result of increased platelet binding and detection of platelet VWF, but reflected specific upregulation of VWF in the vessel wall of lung capillaries.

In agreement with recent findings on the distribution of thrombomodulin in the mouse lung (32), immunohistochemical stain- ing revealed widespread expression of thrombomodulin throughout the lung of young and old control mice ( Fig. 5A). Thrombomodulin lined the endothelium of small and capillary blood vessels, but was also expressed by lung epithelium ( Fig. 5A), slightly more in old than in young mice. Since immunohistochemical evaluation did not allow appreciating differences in thrombomodulin expression for 'tunnel-filtered' and 'tunnel-exposed' mice, batch analysis was performed on lung extracts via Western blotting for thrombomodulin, followed by digital imaging of the intensity of the bands. Analysis of the thrombomodulin band intensity for control, 'tunnel-filtered' and 'tunnel-exposed' young and old animals, in comparison to similarly scanned $\beta$-actin bands showed that the normalised thrombomodulin intensity dropped both in young and old 'tunnel-exposed' and 'tunnel-filtered' animals ( Fig. 5B).

\section{Markers of BP and endothelial cell activation}

Baseline plasma values for sP-sel and VWF were higher in old vs. young mice. Traffic-related air pollution upregulated the plasma

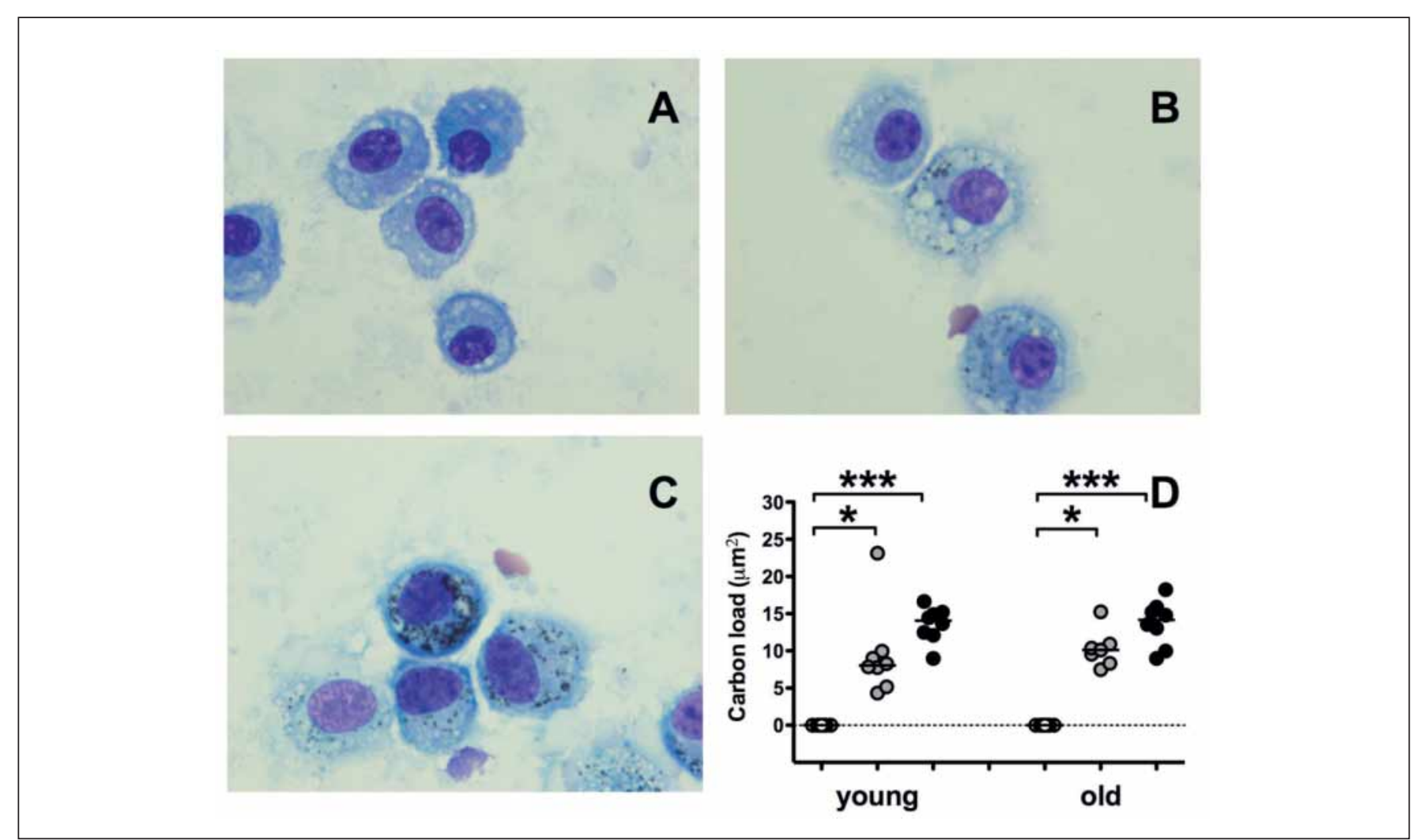

Figure 2: Microscopic images of BALF cells and carbon load. A-C) Microscopic image of cytospins of bronchoalveolar lavage fluid (BALF) cells from young mice placed in a cage in the clean environment $(A)$, a filtered cage inside the roadside tunnel (B) and an unfiltered cage inside the tunnel (C). Carbon particles are obvious in macrophages for both tunnel groups. D) Measurement of carbon load in alveolar macrophages from young and old mice, as indicated, placed in a clean environment ('clean', white dots), in filtered cages inside the tunnel ('tunnel-filtered', grey dots) or in unfiltered cages inside the tunnel ('tunnel-exposed', black dots). Data are represented as a scatter dot plot with median values. Dotted line represents baseline median value (= value for the 'clean' group) for the young mice. * $p<0.05$, $* * * p<0.001$. 
concentration of sP-sel in young mice, with trends towards similar elevations in the concentration of sE-sel and VWF. No differences were observed between 'tunnel-filtered' and 'tunnel-exposed' groups. Values in old mice were not significantly altered by air pollution exposure (Fig. 6). Both in young and old mice, the plasma levels of the specific endothelial marker sE-sel correlated strongly with levels of sP-sel $\left(\mathrm{p}<0.0001, \mathrm{r}^{2}: 0.605\right.$ and $\mathrm{p}=0.0035, \mathrm{r}^{2}: 0.386$, respectively), in agreement with endothelial cell activation. Plasma sE-sel also correlated with VWF in young and old mice $\left(\mathrm{p}=0.02, \mathrm{r}^{2}\right.$ : 0.312 and $\mathrm{p}=0.05, \mathrm{r}^{2}: 0.200$, respectively).

\section{Microvesicles}

Baseline values for all investigated microvesicle populations were similar between old and young mice. The majority of microvesicles bound annexin V, a measure for their surface exposure of procoagulant negatively charged phospholipids. In contrast to the young mice, a trend towards increased levels of BP- $\mu \mathrm{V}$ (total, AVand $\mathrm{AV}+$ ) was observed for the old mice in the tunnel, with the highest values for the 'exposed' group ( Fig. 7). Total BP- $\mu \mathrm{V}$ numbers correlated with circulating BP numbers in young mice $\left(\mathrm{p}=0.01, \mathrm{r}^{2}: 0.279\right)$ and to a lesser extent in old mice $\left(\mathrm{p}=0.07, \mathrm{r}^{2}\right.$ : 0.171 ). No correlations were found between RBC- $\mu \mathrm{V}$ and circulating $\mathrm{RBC}$.

\section{Coagulation}

Baseline values were higher in old vs. young mice for FVIII, but not for FVII or fibrinogen, or for any of the thrombin generation (TG) parameters. ETP in the 'tunnel filtered' group was significantly higher than in the 'clean' group for young mice, when TG was measured upon addition of both phospholipids and TF. No air pollution-induced changes were observed in any of the other coagulation parameters ( Table 1$)$.

\section{Discussion}

Young and old mice were continuously exposed to traffic-related air pollution in an urban roadside tunnel for more than three weeks, in unfiltered or filtered cages and compared to controls kept in a clean environment. Thus, haemostatic complications of traffic-related air pollution were investigated in a real-life condition, over a time-window, exceeding that of commonly applied experimental acute and subacute time-windows (25). Exposure for 25/26 days to intermittently high $\mathrm{PM}_{10}$ (and $\mathrm{PM}_{2.5}$ ) levels induced carbon particle uptake by resident lung macrophages, and triggered subtle changes in the pulmonary circulation and blood, suggestive of thrombogenic changes in the microvasculature. In old mice, relative changes in relevant parameters were smaller, in agreement

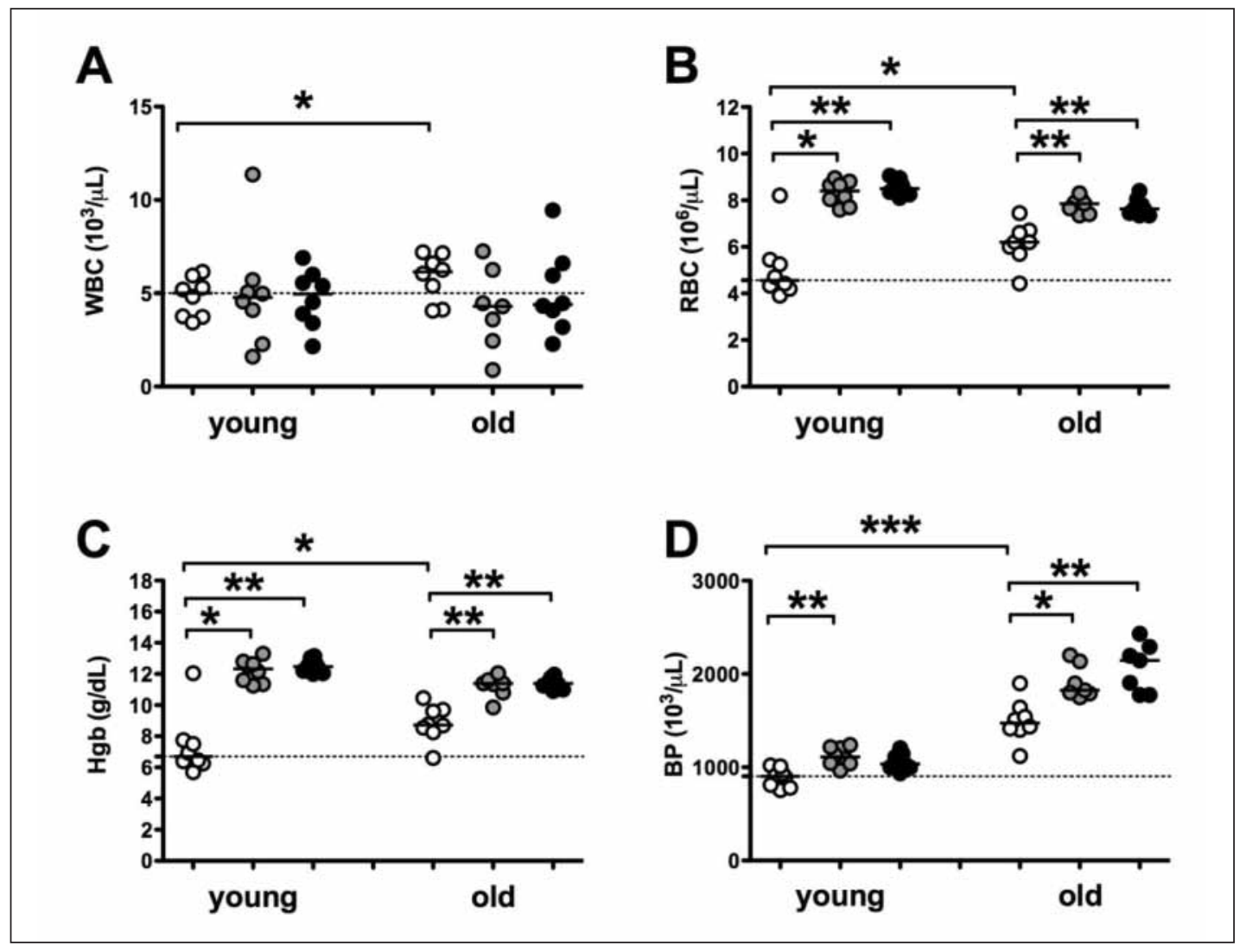

Thrombosis and Haemostasis 108.4/2012
Figure 3: Blood cell parameters after exposure. A) White blood cells (WBC), B) red blood cells (RBC), C) haemoglobin ( $\mathrm{Hgb})$ and D) blood platelets (BP) in blood from young and old mice, as indicated; ('clean', white dots; 'tunnel-filtered', grey dots and 'tunnel-exposed', black dots). Data are represented as a scatter dot plot with median values. Dotted line represents baseline median value (= value for the 'clean' group) for the young mice. ${ }^{*} p<0.05$, ** $p<0.01$, *** $p<0.001$. 
with already higher baseline values, but the highest values for blood platelet numbers, sP-sel, VWF, BP microvesicles measured in this study were encountered in old exposed mice, compatible with a collectively higher attributable cardiovascular risk in old mice.
Our study also addressed pulmonary endothelial cell changes associated with continuous traffic-related air pollution. Thus, a mild drop in pulmonary expression of the anticoagulant protein thrombomodulin was found, in agreement with mouse studies, in which
Figure 4: VWF in the lung after exposure. VWF concentration, present in detergent extracts derived from the lungs of young and old mice, as indicated ('clean', white dots; 'tunnel-filtered', grey dots and 'tunnel-exposed', black dots), before (A) and after (B) normalisation vs. the total protein concentration in the extract. Representative images (left: low magnification, right: high magnification) of immuno-histochemical staining for VWF in lung tissues derived from young mice (C). While large blood vessels stained positive in all three groups, the majority of smaller blood vessels did not stain in the 'clean' group, but stained moderately to strongly positive in both tunnel groups. Arrows indicate alveolar macrophages. AW= large airways; white bars equal $100 \mu \mathrm{m} .{ }^{*} \mathrm{p}<0.05$, * * $p<0.01,{ }^{* * *} p<0.001$.

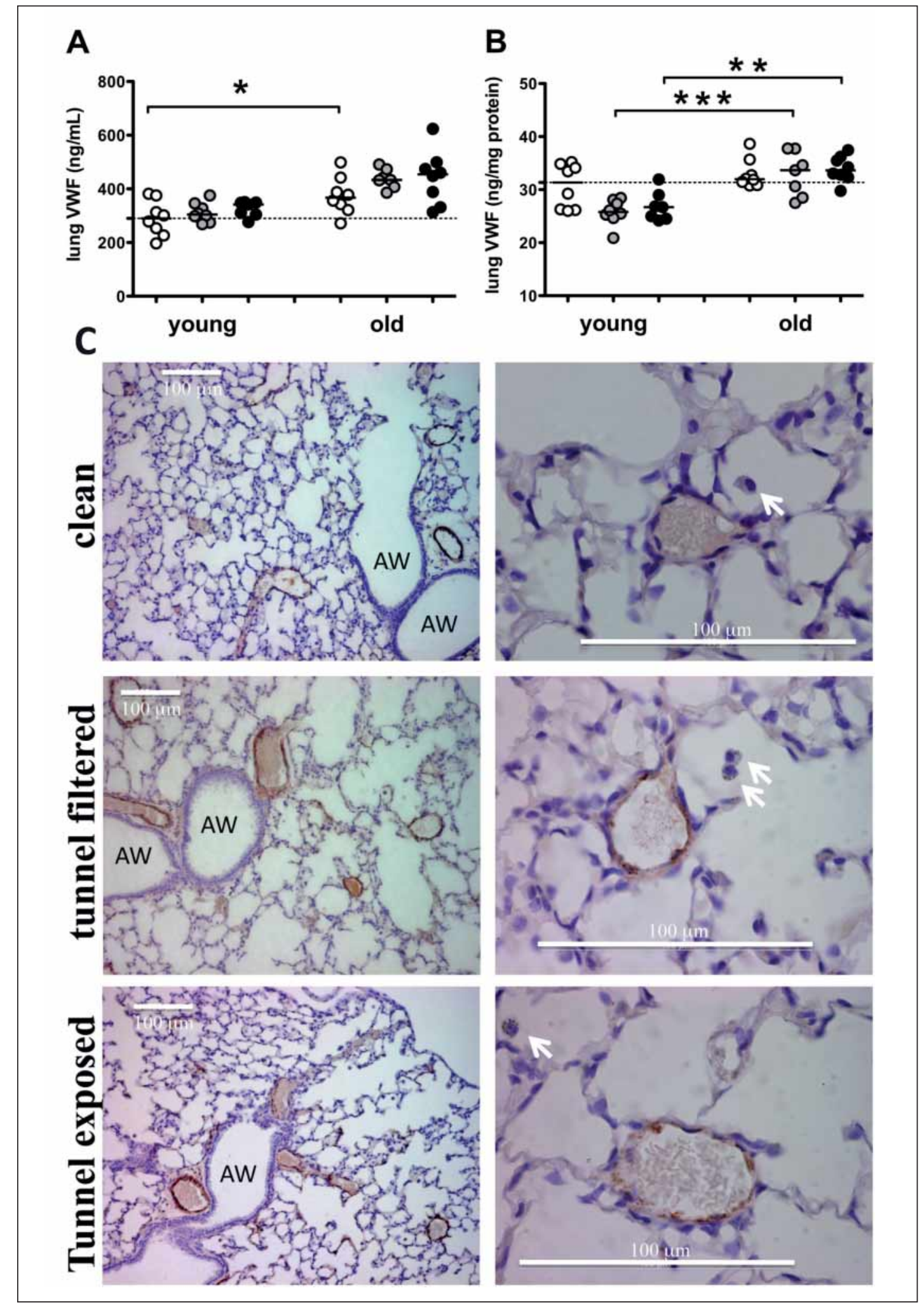

Thrombosis and Haemostasis 108.4/2012 
Sirt1-dependent downregulation of thrombomodulin was observed, upon exposure to particulate matter (32), further in line with recent findings in children (33). Although the total pulmonary VWF-expression was not affected by exposure to polluted air in the tunnel, semi-quantitative immunohistochemical analysis of lung sections pointed to increased VWF expression in the endothelium, especially in lung capillaries, suggestive of endothelial cell activation in the pulmonary microcirculation. Also in humans, altered endothelial cell function was demonstrated upon exposure to diluted diesel exhaust $(34,35)$, these adverse vascular effects recently having been attributed to the nanoparticulate fraction, present in diesel exhaust (36).

Plasma sE-sel (specific marker for endothelial cell activation), sP-sel and VWF strongly correlated with each other, even when sPsel, sE-sel and VWF only increased modestly upon exposure ( Fig. 6). Platelet-endothelial interactions activate platelets in a VWF-dependent manner (37), and P-sel is implicated in blood platelet activation upon intratracheal instillation of carbon nanotubes in mice (38). In conjunction with the direct activation of blood platelets by particulate matter (39), platelet-endothelial interactions lead to platelet degranulation, further raising sP-sel and VWF in plasma. In old mice, sP-sel and VWF were significantly elevated at baseline; no statistically significant upregulation was observed upon air pollution exposure, yet, the highest sP-sel and VWF antigen levels were encountered in exposed old mice. At present, it is unclear whether endothelial cells are directly activated upon subchronic transepithelial passage of ultrafine particles in the lung as is the case for platelets $(39,40)$.

Negatively charged phospholipids can promote coagulation through surface-bound TF (24). Elevated numbers of circulating microvesicles have been demonstrated in patients with venous thromboembolism (41), and pathophysiological procoagulant changes are believed to be more pronounced after chronic exposure (25). We observed a trend towards higher levels of total BP- $\mu \mathrm{V}$ for old mice located inside the tunnel, with the highest median values for the 'exposed' group. No changes were observed in microvesicle numbers for young mice. As the majority of $\mathrm{BP}-\mu \mathrm{V}$ in the present study bound annexin $V$, a measure for the surface expression of negatively charged phospholipids, the air pollution-induced increase of their numbers reflects a procoagulant risk factor in the old mice. All thrombin generation measurements were performed in the presence of an excess of exogenously added phospholipids. Therefore, these assays are insensitive to the phos-

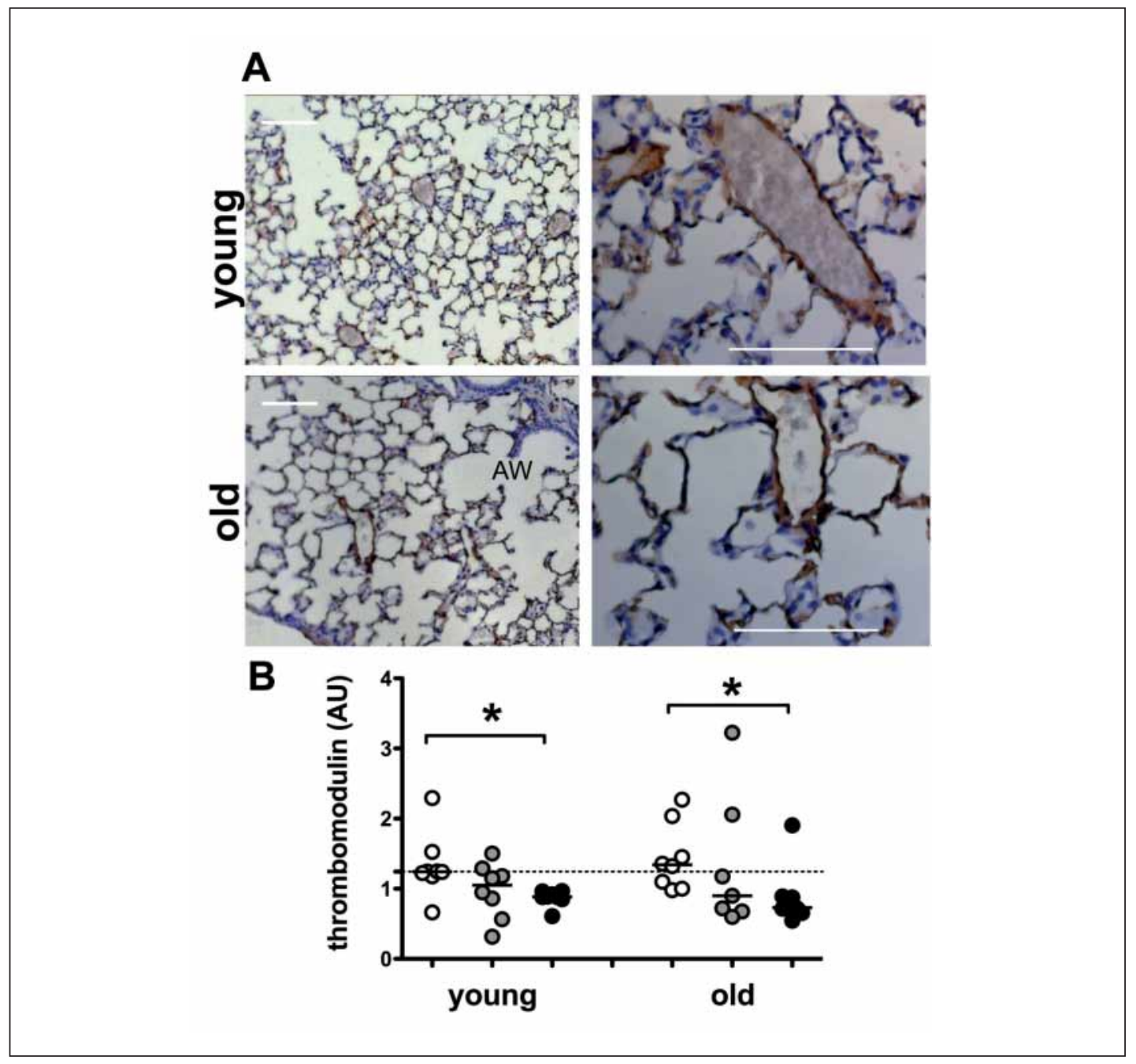

Thrombosis and Haemostasis 108.4/2012
Figure 5: Thrombomodulin in the lung after exposure. Representative distribution of thrombomodulin (left: low magnification, right: high magnification) over blood vessels and epithelium, in young and old mouse lungs, as indicated. AW= large airways; white bars equal $100 \mu \mathrm{m}(\mathrm{A})$. Thrombomodulin band intensity, normalised to $\beta$-actin intensity, after SDS-PAGE, transfer on nitrocellulose and Western blotting of detergent extracts from the lungs of control, "tunnel-filtered" and "tunnel-exposed" young and old mice ('clean', white dots; 'tunnel-filtered', grey dots and 'tunnel-exposed', black dots). Stained bands were digitally quantified and expressed as arbitrary units (AU); $B)$ * $p<0.05$.

(C) Schattauer 2012 
pholipid-dependent procoagulant state observed in the old mice exposed to air pollution. Moreover, in the absence of changes in any of the measured coagulation factors, no enhanced TG was observed under any condition, except for a small increase in ETP for the 'tunnel filtered' group of the young mice. Antithrombin and protein $\mathrm{C}$ were not assessed in the present study.

Our findings are in part comparable to a recent study in which rats were exposed to diesel engine exhaust and to roadside particulate matter for four weeks, five days/week at $6 \mathrm{~h} /$ day (42). Diesel engine exhaust and concentrated PM administered ranged from 174, over 214 to $485 \mu \mathrm{g} / \mathrm{m}^{3}$. While continuously exposed to the traffic, in our study, mice confronted PM at $300 \mu \mathrm{g} / \mathrm{m}^{3}$ on working days, during morning and evening traffic, up to $400 \mu \mathrm{g} / \mathrm{m}^{3}$ at peak moments. In contrast to the careful monitoring of the gaseous pollutant concentrations in the rat study (42), we could not monitor gas levels in the roadside tunnel, i.e. we cannot further split up the mild effects observed, as a function of contributions by particulate and gaseous air pollutants. Earlier work by the same authors had revealed an association between platelet activation and levels of nitric oxide $(\mathrm{NO})$, nitrogen dioxide $\left(\mathrm{NO}_{2}\right)$ and carbon monoxide $(\mathrm{CO})(8)$, an association not investigated by us. Gerlofs-Nijland (42) found that exposure of rats to $800 \mu \mathrm{g} / \mathrm{m}^{3} \mathrm{O}_{3}$ for $12 \mathrm{~h}$ increased lung permeability, triggering slight inflammation of polymorphonuclear neutrophils in alveoli after $24 \mathrm{~h}$. However, since both our and their study show alveolar macrophage loading with PM, but no PMN inflammation, the impact of ozone $\left(\mathrm{O}_{3}\right)$ appears minimal in both studies.
The mild inflammation in rats (42) has been explained by an adequate host defence system, a conclusion presently corroborated for the mouse. Already during intratracheal administration of diesel exhaust particles to the mouse, several-fold higher doses were required than anticipated from human epidemiological studies (23), a conclusion not valid for the hamster, where low diesel exhaust exposure triggers potent prothrombotic amplification (39). Therefore, the finding that the tunnel air exposure raised both RBC (also haemoglobin) and BP numbers, over an interval as short as 25 days, both in young and old mice, was surprising. It is difficult to correctly interpret this, against the rise in oxidative stress in lungs and bone marrow, enhancing haematopoiesis (43), or via alternative explanations, such as hypoxia, translocation via the epithelial-endothelial barrier of macrophages loaded with PM, or exposure to gaseous pollutants such as $\mathrm{CO}$ or sulfur dioxide $\left(\mathrm{SO}_{2}\right)$ (44-46) or to stress (e.g. caused by noise) inducing adaptative upregulation of growth factors $(47,48)$. In diabetic subjects, we also found a correlation between chronic air pollution exposure and BP numbers (27). Yet, the red blood cell count does not correlate positively with $\mathrm{PM}_{10}$ (49), whereas the causal relationship between exposure to hydrogen sulfide $\left(\mathrm{H}_{2} \mathrm{~S}\right)$, respectively $\mathrm{SO}_{2}(44,46)$ and RBC elevation, has become improbable, since modern diesel fuel hardly contains sulphurous substances. In view of its documented effects on the numbers of circulating nucleated RBCs in neonates, born from mothers exposed during pregnancy (50), CO seems the best candidate for this effect.
Figure 6: Markers of endothelial and blood platelet function. A) soluble P-selectin (sPsel), B) soluble E-selectin (sE-sel), C) platelet factor 4 (PF4) and D) von Willebrand factor antigen (VWFag) levels in plasma from young and old mice, as indicated; ('clean', white dots; 'tunnel-filtered', grey dots and 'tunnel-exposed', black dots). Data are represented as a scatter dot plot with median values. Dotted line represents baseline median value (= value for the 'clean' group) for the young mice. ${ }^{*} p<0.05, * *$ $p<0.01$.

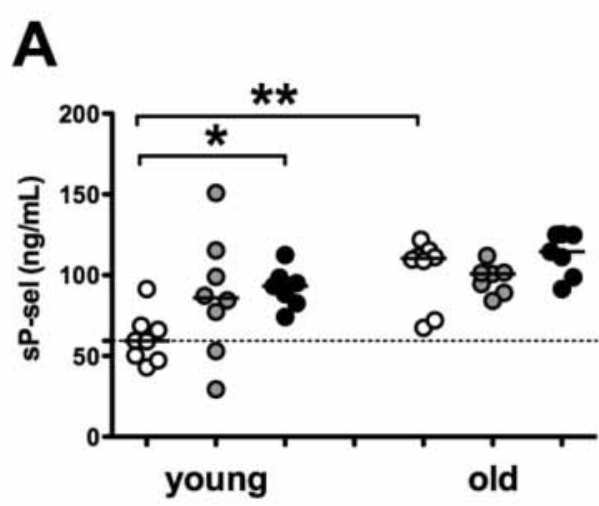

C

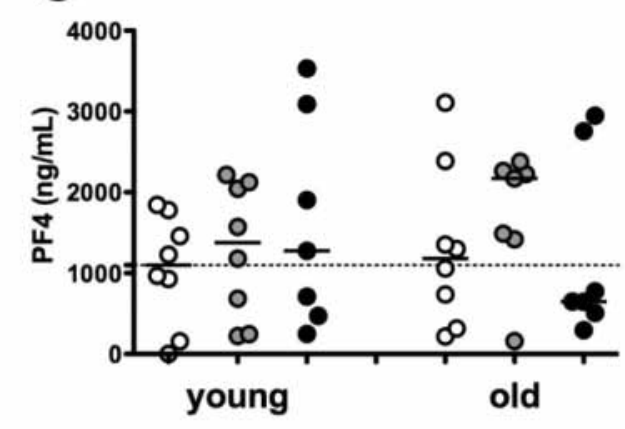

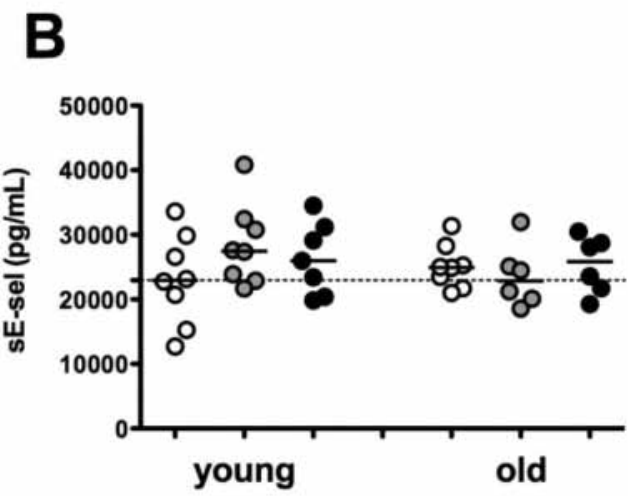

D

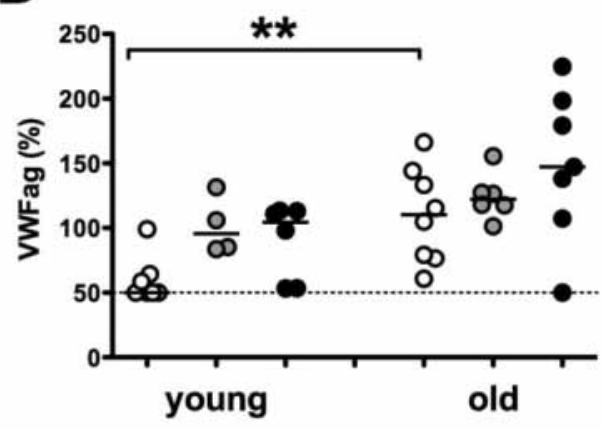


The paucity of changes in secondary haemostasis parameters is in agreement with previous findings of our group $(23,25)$, and can be explained by absent lung inflammation and IL-6 production in alveolar macrophages $(51,52)$. Intratracheal instillation of ultrafine particles, collected near a roadside tunnel caused a TF-driven increase in thrombin generation at $4 \mathrm{~h}$, and a contact activationdriven increase at $20 \mathrm{~h}$ (53). On the other hand, reduced lung tissue factor activity, in conjunction with reduced lung tissue thrombin generation (42), was found by others. The present study illustrates that a 25/26 day exposure of young healthy mice to moderate air pollution activates in the first place primary, but not secondary haemostasis pathways, only triggered at much higher concentrations in acute experimental exposure studies.

The 'tunnel-filtered' group were unexpectedly similar to the 'tunnel-exposed' group. Several explanations may apply: first, fil- tering reduced the exposure of mice considerably, but not completely. Indeed, $\mathrm{PM}_{2.5}$ were filtered less efficiently $(-32 \%)$ than $\mathrm{PM}_{10}(-59 \%)$ and ultrafine particles are propably poorly filtered. In view of their major impact on cardiovascular status (9) and in view of the presence of gaseous components in the polluted air, we cannot exclude these factors, or other environmental factors (car light, noise, stress), identical for both groups to play a role in the effects observed.

In conclusion, continuous inhalation for 25/26 days of polluted air triggers platelet and endothelial cell activation, especially in young mice. However, higher baseline values of platelet and endothelial cell activation markers, of the number of circulating blood platelets and of FVIII, in combination with a pollution-related increase in the numbers of blood platelets, platelet activation markers and blood platelet-derived microvesicles, collectively in-

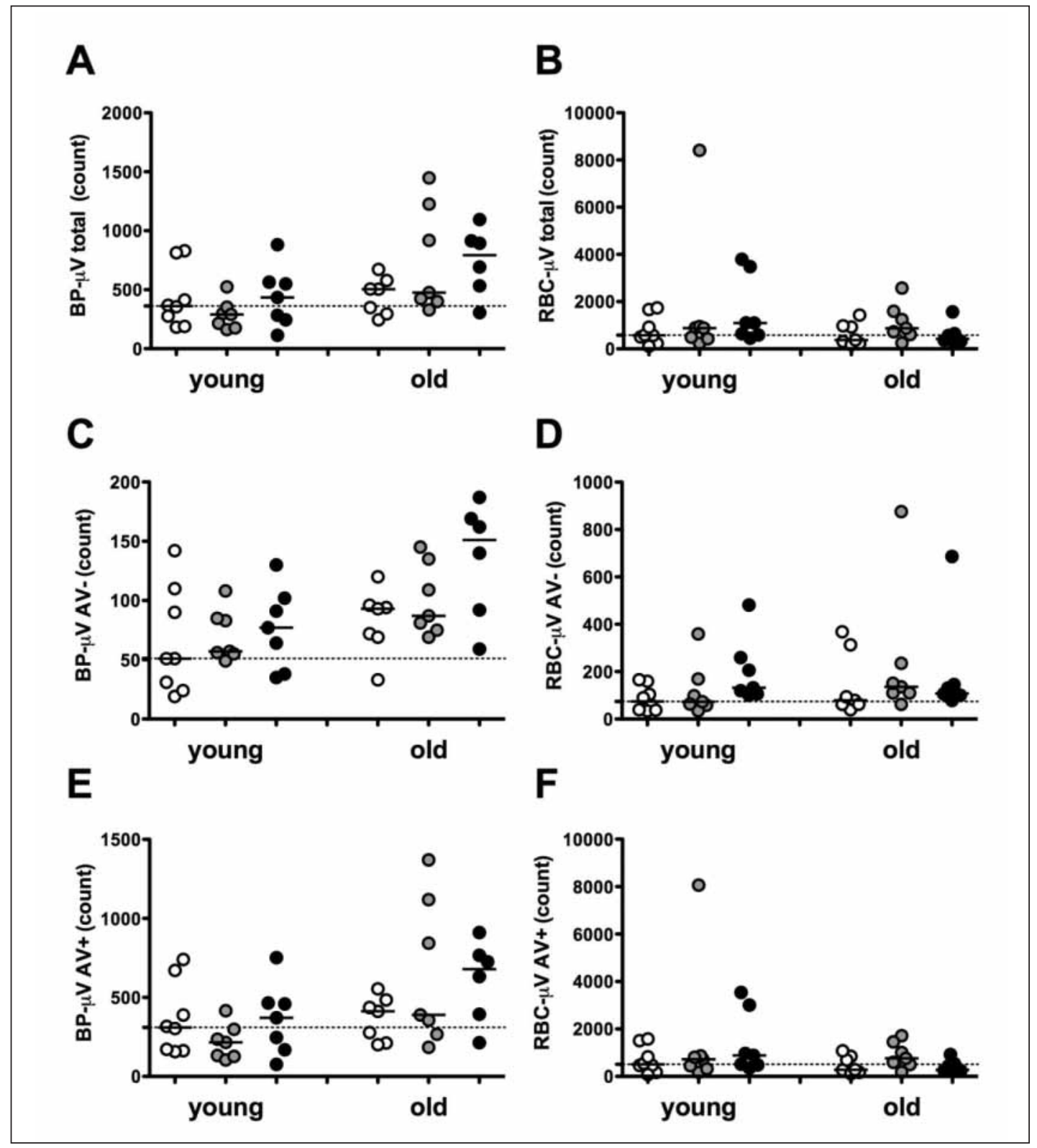

Thrombosis and Haemostasis 108.4/2012
Figure 7: Microvesicle numbers in plasma after exposure. A) Blood platetelet-derived microvesicles (BP- $\mu \mathrm{V}), \mathrm{B})$ red blood cell-derived microvesicles (RBC- $\mu \mathrm{V}$ ), C) $B P-\mu V$ that do no bind annexin V (BP- $\mu \mathrm{V}$ AV-), D) $R B C--\mu V$ that do not bind annexin $V(R B C-\mu V$ $A V-), E) B P-\mu V$ that bind annexin $\mathrm{V}(\mathrm{BP}-\mu \mathrm{V} \mathrm{AV}+)$ and F) $R B C-\mu V$ that bind annexin $\mathrm{V}(\mathrm{RBC}-\mu \mathrm{V} \mathrm{AV}+)$, measured by flow cytometry, in plasma from young and old mice, as indicated; ('clean', white dots; 'tunnel-filtered', grey dots and 'tunnel-exposed', black dots). Data are represented as a scatter dot plot with median values. Dotted line represents baseline median. 


\section{What is known about this topic?}

- Acute exposure to polluted air rapidly leads to cardiovascular complications, primarily due to inhalation of ultrafine particulate matter.

- Short-term exposure triggers arterial thrombogenicity; the haemostatic risk profile after long-term exposure is less clear.

\section{What does this paper add?}

- Continuous exposure of mice to traffic-related air pollution, in a real-life setting leads to activation of pulmonary endothelium, without overt pulmonary inflammation, accompanied by reduced thrombomodulin expression, elevated von Willebrand factor (VWF) expression, and release of VWF and E-/P-selectin in the circulation.

- Exposure triggers stronger changes for most parameters in young mice, compared to aged mice with higher baseline values, but blood platelet and platelet microvesicle numbers rise more in exposed aged mice.

- The attributable risk for intrinsic thrombogenicity rises to higher values upon exposure to traffic-related air pollution at an older age.

dicate a boost in thrombogenicity in exposed old mice. Experimental thrombosis studies will need to confirm a gain in thrombotic risk profile for exposure at advanced age.

\section{Acknowledgements}

The authors would like to thank Peter De Leenheir, Guido Cole and Stefaan Hoornaert from the Department Mobility and Public Works of the Flemmish Government for practical assistance in the tunnel and for providing the tunnel transit data, respectively. J. Emmerechts is holder of a grant from the Institute for the Promotion of Innovation through Science and Technology in Flanders (IWT-Vlaanderen, project 81045). For part of this work, J. Emmerechts received the CSL Behring Heimburger Award in 2011. J. A. J. Vanoirbeek and V. De Vooght are post-doctoral fellows of the FWO Flanders. Support to B. Nemery by the FWO Flanders (grant G.0905.11) is greatly appreciated. The CMVB is supported by the "Programmafinanciering KULeuven" (PF/10/014).

\section{Conflicts of interest}

None declared.

\section{References}

1. Baccarelli A, Martinelli I, Zanobetti A, et al. Exposure to particulate air pollution and risk of deep vein thrombosis. Arch Intern Med 2008; 168: 920-927.

2. Dominici F, McDermott A, Daniels M, et al. Mortality among residents of 90 cities. In Revised Analyses of Time-Series Studies of Air Pollution and Health. Boston, MA: Health Effects Institute 2003; 9-24.

3. Hoek G, Brunekreef B, Goldbohm S, et al. Association between mortality and indicators of traffic-related air pollution in the Netherlands: a cohort study. Lancet 2002; 360: 1203-1209.

4. Katsouyanni K, Touloumi G, Samoli E, et al. Confounding and effect modification in the short-term effects of ambient particles on total mortality: results from 29 European cities within the APHEA2 project. Epidemiology 2001; 12: 521-531.
5. Pope CA, 3rd, Burnett RT, Thurston GD, et al. Cardiovascular mortality and longterm exposure to particulate air pollution: epidemiological evidence of general pathophysiological pathways of disease. Circulation 2004; 109: 71-77.

6. Samet JM, Rappold A, Graff D, et al. Concentrated ambient ultrafine particle exposure induces cardiac changes in young healthy volunteers. Am J Respir Crit Care Med 2009; 179: 1034-1042.

7. Samoli E, Peng R, Ramsay T, et al. Acute effects of ambient particulate matter on mortality in Europe and North America: results from the APHENA study. Environ Health Perspect 2008; 116: 1480-1486.

8. Rudez G, Janssen NA, Kilinc E, et al. Effects of ambient air pollution on hemostasis and inflammation. Environ Health Perspect 2009; 117: 995-1001.

9. Brook RD, Rajagopalan S, Pope CA, 3rd, et al. Particulate matter air pollution and cardiovascular disease: An update to the scientific statement from the American Heart Association. Circulation 2010; 121: 2331-2378.

10. Peters A, Dockery DW, Muller JE, et al. Increased particulate air pollution and the triggering of myocardial infarction. Circulation 2001; 103: 2810-2815.

11. Lucking AJ, Lundback M, Mills NL, et al. Diesel exhaust inhalation increases thrombus formation in man. Eur Heart J 2008; 29: 3043-3051.

12. Mills NL, Tornqvist H, Gonzalez MC, et al. Ischemic and thrombotic effects of dilute diesel-exhaust inhalation in men with coronary heart disease. N Engl J Med 2007; 357: 1075-1082.

13. Hoffmann B, Moebus S, Mohlenkamp S, et al. Residential exposure to traffic is associated with coronary atherosclerosis. Circulation 2007; 116: 489-496.

14. Baccarelli A, Martinelli I, Pegoraro V, et al. Living near major traffic roads and risk of deep vein thrombosis. Circulation 2009; 119: 3118-3124.

15. Sacks JD, Stanek LW, Luben TJ, Johns DO, Buckley BJ, Brown JS, et al. Particulate matter-induced health effects: who is susceptible? Environ Health Perspect 2011; 119: 446-454.

16. Goldberg MS, Burnett RT, Bailar JC, 3rd, et al. The association between daily mortality and ambient air particle pollution in Montreal, Quebec. 2. Cause-specific mortality. Environ Res 2001; 86: 26-36.

17. Pope CA, 3rd, Renlund DG, Kfoury AG, et al. Relation of heart failure hospitalization to exposure to fine particulate air pollution. Am J Cardiol 2008; 102: $1230-1234$.

18. Larrieu S, Jusot JF, Blanchard M, et al. Short term effects of air pollution on hospitalizations for cardiovascular diseases in eight French cities: the PSAS program. Sci Total Environ 2007; 387: 105-112.

19. Anderson HR, Atkinson RW, Bremner SA, et al. Particulate air pollution and hospital admissions for cardiorespiratory diseases: are the elderly at greater risk? Eur Respir J Suppl 2003; 40: 39s-46s.

20. Lloyd-Jones DM, Larson MG, Beiser A, et al. Lifetime risk of developing coronary heart disease. Lancet 1999; 353: 89-92.

21. Naess IA, Christiansen SC, Romundstad P, et al. Incidence and mortality of venous thrombosis: a population-based study. J Thromb Haemost 2007; 5: 692-699.

22. Emmerechts J, Loyen S, Hoylaerts MF. Microparticle number or procoagulant activity are not upregulated in healthy elderly persons. Thromb Res 2012; 129: 98-100.

23. Emmerechts J, Alfaro-Moreno E, Vanaudenaerde BM, et al. Short-term exposure to particulate matter induces arterial but not venous thrombosis in healthy mice. J Thromb Haemost 2010; 8: 2651-2661.

24. Morel O, Toti F, Hugel B, et al. Procoagulant microparticles: disrupting the vascular homeostasis equation? Arterioscler Thromb Vasc Biol 2006; 26: 2594-2604.

25. Emmerechts J, Jacobs L, Van Kerckhoven S, et al. Air Pollution-Associated Procoagulant Changes: role of Circulating Microvesicles. J Thromb Haemost 2012; 10: $96-106$.

26. Kulkarni NS, Prudon B, Panditi SL, et al. Carbon loading of alveolar macrophages in adults and children exposed to biomass smoke particles. Sci Total Environ 2005; 345: 23-30.

27. Jacobs L, Emmerechts J, Mathieu C, et al. Air pollution related prothrombotic changes in persons with diabetes. Environ Health Perspect 2010; 118: 191-196.

28. Hemmeryckx B, Emmerechts J, Bovill EG, et al. Effect of ageing on the murine venous circulation. Histochem Cell Biol 2012; 137: 537-546.

29. Moura R, Tjwa M, Vandervoort P, et al. Thrombospondin-1 deficiency accelerates atherosclerotic plaque maturation in ApoE-/- mice. Circ Res 2008; 103: $1181-1189$.

30. Hemmeryckx B, Van Hove CE, Fransen P, et al. Progression of the prothrombotic state in aging Bmal1-deficient mice. Arterioscler Thromb Vasc Biol 2011; 31: 2552-2559. 
31. Peters LL, Cheever EM, Ellis HR, et al. Large-scale, high-throughput screening for coagulation and hematologic phenotypes in mice. Physiol Genomics 2002; 11 : 185-193.

32. Wu Z, Liu MC, Liang M, et al. Sirtl protects against thrombomodulin downregulation and lung coagulation following particulate matter exposure. Blood 2012; 119: 2422-2429.

33. Poursafa P, Kelishadi R, Lahijanzadeh A, et al. The relationship of air pollution and surrogate markers of endothelial dysfunction in a population-based sample of children. BMC Public Health 2011; 11: 115.

34. Mills NL, Tornqvist H, Robinson SD, et al. Diesel exhaust inhalation causes vascular dysfunction and impaired endogenous fibrinolysis. Circulation 2005; 112 : $3930-3936$.

35. Tornqvist H, Mills NL, Gonzalez M, et al. Persistent endothelial dysfunction in humans after diesel exhaust inhalation. Am J Respir Crit Care Med 2007; 176: 395-400.

36. Mills NL, Miller MR, Lucking AJ, et al. Combustion-derived nanoparticulate induces the adverse vascular effects of diesel exhaust inhalation. Eur Heart J 2011; 32: $2660-2671$

37. Theilmeier G, Michiels C, Spaepen E, et al. Endothelial von Willebrand factor recruits platelets to atherosclerosis-prone sites in response to hypercholesterolemia. Blood 2002; 99: 4486-4493.

38. Nemmar A, Hoet PH, Vandervoort P, et al. Enhanced peripheral thrombogenicity after lung inflammation is mediated by platelet-leukocyte activation: role of P-selectin. J Thromb Haemost 2007; 5: 1217-1226.

39. Nemmar A, Hoet PH, Dinsdale D, et al. Diesel exhaust particles in lung acutely enhance experimental peripheral thrombosis. Circulation 2003; 107: 1202-1208.

40. Nemmar A, Hoet PH, Vanquickenborne B, et al. Passage of inhaled particles into the blood circulation in humans. Circulation 2002; 105: 411-414.

41. Chirinos JA, Heresi GA, Velasquez H, et al. Elevation of endothelial microparticles, platelets, and leukocyte activation in patients with venous thromboembolism. J Am Coll Cardiol 2005; 45: 1467-1471.
42. Gerlofs-Nijland ME, Totlandsdal AI, Kilinc E, et al. Pulmonary and cardiovascular effects of traffic-related particulate matter: 4 -week exposure of rats to roadside and diesel engine exhaust particles. Inhal Toxicol 2010; 22: 1162-1173.

43. Motohashi H, Kimura M, Fujita R, et al. NF-E2 domination over Nrf2 promotes ROS accumulation and megakaryocytic maturation. Blood 2010; 115: 677-686.

44. Baskurt OK, Levi E, Caglayan S, et al. Hematological and hemorheological effects of air pollution. Arch Environ Health 1990; 45: 224-228.

45. Chen KC, Lee EW, McGrath JJ. Effect of intermittent carbon monoxide inhalation on erythropoiesis and organ weights in rats. J Appl Toxicol 1984; 4: 145-149.

46. Saadat M, Bahaoddini A. Hematological changes due to chronic exposure to natural gas leakage in polluted areas of Masjid-i-Sulaiman (Khozestan province, Iran). Ecotoxicol Environ Saf 2004; 58: 273-276.

47. Goldberg ED, Dygai AM, Zakharova O, et al. The modulating influence of enkephalins on the bone marrow haemopoiesis in stress. Folia Biol 1990; 36:319-331.

48. Ratajczak MZ, Kuczynski WI, Onodera K, et al. A reappraisal of the role of insulin-like growth factor I in the regulation of human hematopoiesis. J Clin Invest 1994; 94: 320-327.

49. Seaton A, Soutar A, Crawford V, et al. Particulate air pollution and the blood. Tho$\operatorname{rax} 1999 ; 54: 1027-1032$.

50. Ziaei S, Nouri K, Kazemnejad A. Effects of carbon monoxide air pollution in pregnancy on neonatal nucleated red blood cells. Paediatr Perinat Epidemiol 2005; 19 : 27-30.

51. Mutlu GM, Green D, Bellmeyer A, et al. Ambient particulate matter accelerates coagulation via an IL-6-dependent pathway. J Clin Invest 2007; 117: 2952-2961.

52. Budinger GR, McKell JL, Urich D, et al. Particulate matter-induced lung inflammation increases systemic levels of PAI-1 and activates coagulation through distinct mechanisms. PLoS One 2011; 6: e18525.

53. Kilinc E, Van Oerle R, Borissoff JI, et al. Factor XII activation is essential to sustain the procoagulant effects of particulate matter. J Thromb Haemost 2011; 9: 1359-1367. 